\title{
THE BIDIRECTIONAL EFFECT OF CREATINE SUPPORTS THE MAINTENANCE OF OXIDANT-ANTIOXIDANT HOMEOSTASIS DURING EXERCISE
}

\author{
Seyhan Taskin ${ }^{1 \rrbracket}$, Hakim Celik ${ }^{1}$, Seniz Demiryurek ${ }^{2}$, Abdullah Taskin ${ }^{3} \bowtie$ \\ Department of Physiology, Faculty of Medical, Harran University, Turkey \\ ${ }^{2}$ Department of Physiology, Faculty of Medical, Gaziantep University, Turkey \\ ${ }^{3}$ Department of Nutrition and Dietetics, Faculty of Health Sciences, Harran University, Turkey.
}

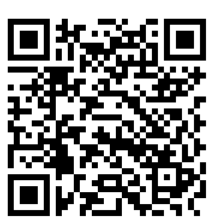

\begin{abstract}
The importance of supplements used with exercise is increasing day by day. This study was aimed at evaluating the effects of creatine monohydrate (CrM) supplementation, during different intensities of exercise, on oxidative stress through dynamic thiol disulfide homeostasis. Forty-two BALB/c mice were used and randomly divided into six groups: control (C), low-intensity exercise (LIE), high-intensity exercise (HIE), C+CrM ( $4 \%$ of daily diet), LIE+CrM, and HIE+CrM groups. The groups performed low-intensity $(8 \mathrm{~m} / \mathrm{min} / 30 \mathrm{~min} /$ day $)$ and high-intensity $(24 \mathrm{~m} / \mathrm{min} / 30 \mathrm{~min} /$ day $)$ exercise on a mouse treadmill for eight weeks. At the end of the experimental period, the thiol disulfide homeostasis levels were analyzed by using a new automated measurement technique. When the native thiol and total thiol values were examined, the difference between the groups was statistically significant $(p=0.029, p=0.035$, respectively). Creatine intake with exercise decreased native thiol and total thiol levels. However, serum disulfide levels were lower in LIE+CrM compared to other study groups, but there was no statistically significant difference. It is thought that creatine supplementation with exercise reduces the thiol-disulfide homeostasis burden of the organism, and that after the depletion of creatine stores, the sustainability of oxidant-antioxidant homeostasis can be extended, thus prolonging the duration of antioxidant resistance.
\end{abstract}

Keywords: Exercise, Creatine, Thiol Disulfide Homeostasis, Oxidative Stress

\section{INTRODUCTION}

Creatine is an ergogenic molecule that contributes significantly to cellular energy metabolism. It can be produced endogenously in body systems, or it can be taken into the body through diet. Cells with high energy requirements use creatine in the form of phosphocreatine (PCr) Havenetidis (2016). Phosphocreatine serves as a source of phosphate to produce adenosine triphosphate (ATP) from adenosine diphosphate (ADP). In particular, skeletal muscle cells store enough ATP and phosphocreatine for approximately 10 seconds of high-intensity activity. Short-term creatine supplementation increases PCr stores by $10 \%$ to $40 \%$, resulting in a $10 \%$ to $30 \%$ total creatine increase Kreider (2003), Momaya et al. (2015). Creatine, which is widely used among athletes, increases intramuscular storage phosphocreatine levels and causes an increase in exercise performance, post-exercise recovery, and muscle mass Poortmans et al. (2010), Harris et al. (1992), Antonio et al. (2021). The use of creatine is not only limited to sports, but is also a nutritional supplement with positive therapeutic effects in various diseases. It has been shown to prevent disease-related muscle atrophy, improve cognitive functions, and have 
antioxidant activity Wallimann et al. (2011). The creatine-phosphocreatine-ATP cycle (alactic anaerobic), the most potent anaerobic energy pathway, together with the anaerobic lactic acid cycle, are the main anaerobic energy providers Gastin (2001), Moghetti et al. (2016).

The aerobic energy system, also known as the oxygen energy system, is the long-term ATP provider of metabolism, interconnected by biochemical junctions and with the electron transport chain (ETC) at its center Moghetti et al. (2016). Exercise, which is an activator of aerobic energy pathways Hargreaves and Spriet (2020), is also the most powerful modulator of metabolism Moghetti et al. (2016). Increased metabolic activities during exercise cause changes in the cellular energy cycle, disrupting the redox balance, and free radicals are released Hargreaves and Spriet(2020), Brunetta et al. (2020), Murphy (2009). Free radicals are usually derived from nitrogen, oxygen, and sulfur molecules Lü et al. (2010). Reactive oxygen species (ROS), which are oxygen-derived free radicals, are produced during cellular metabolism and functional activities and have important roles in cell signaling and apoptosis Cao et al. (2017). However, excessive amounts of ROS have harmful effects on many biomolecules, including protein, lipid, RNA, and DNA, as they are very small and highly reactive Waris and Ahsan (2006). Theoretically, exercise-induced ROS production is like a double-edged sword. Moderate ROS production during exercise promotes positive physiological adaptations in active skeletal muscles, while high ROS production damages macromolecular structures Vargas-Mendoza et al. (2019).

Aerobic and anaerobic energy systems work simultaneously, not independently of each other, to provide the energy needed for exercise. In the face of increasing energy demand, it is aimed at refilling the intracellular ATP pools by increasing the activity of all energy systems. However, the anaerobic energy system (from milliseconds to seconds) activates much faster than the aerobic system (from seconds to minutes). The energy obtained from the creatine phosphate and glycolytic system in the first moments at the beginning of the exercise compensates for the energy deficit caused by the delay in the aerobic system. For this reason, PCr is especially important as a valuable storage energy source in anaerobic energy systems Bediz (2020). The presence of ATP is critical for skeletal muscle contraction, both in explosive power and in sprinting activities that last seconds or minutes and in endurance exercises that last for hours. Since the increase in metabolic rate during the transition from rest to exercise can be more than 100 times greater, the rapid supply of ATP and preservation of ATP content in muscle cells are critical for maintaining activity Hargreaves and Spriet (2020).

Despite the many beneficial effects of exercise, its potential to create oxidative stress in relation to its intensity and duration is one of its most important limitations. Increased muscle phosphocreatine levels with exercise may contribute to an increase in exercise performance, regulation of energy conversions, and maintenance of oxidant-antioxidant homeostasis. In this study, thiol-disulfide levels, which indicate systemic oxidant-antioxidant homeostasis levels, were investigated in mice that underwent low-intensity and high-intensity exercise with creatine monohydrate supplementation.

\section{MATERIALS AND METHODS}

\section{Animals}

The experimental protocol was approved by the Animal Ethics Committee of the University (No: 2019/004) and was conducted under the National Institute of 
Health's Guidelines for the Care and Use of Laboratory Animals and the Declaration of Helsinki. Forty-two male BALB/c mice aged 8-10 weeks from our animal facility were maintained in conditions that were controlled for temperature $\left(22 \pm 1{ }^{\circ} \mathrm{C}\right)$, humidity (50-60\%), and $12 \mathrm{~h}$ dark/light cycle with food and water ad libitum. The mice were divided into 6 groups, with 7 animals in each group, as follows: control (C), low-intensity exercise (LIE), high-intensity exercise (HIE), C + creatine monohydrate $(\mathrm{CrM})(\mathrm{C}+\mathrm{CrM})$, low-intensity exercise + $\mathrm{CrM}(\mathrm{LIE}+\mathrm{CrM})$, and highintensity exercise + $\mathrm{CrM}(\mathrm{HIE}+\mathrm{CrM})$. In the $\mathrm{CrM}$ group, the mice were fed on a diet supplemented with $4 \%$ creatine monohydrate, while other groups were fed on a standard rodent diet for 8 weeks Leem et al. (2018).

\section{Exercise Protocol}

The mice in the exercise groups performed running exercises on a 5 -lane rodent motor-driven treadmill (Ugo Basile, Animal Treadmill, ITALY) for 5 days/week and 8 weeks. The exercise groups performed training exercises at a speed of $4 \mathrm{~m} / \mathrm{min}$ for 5 minutes for a week before starting the experiment The LIE group was run at a speed of $8 \mathrm{~m} / \mathrm{min}$ at a $0^{\circ}$ incline for $30 \mathrm{~min}$ until the end of the eighth week after a one-week exercise adaptation period. The HIE group was run at a speed of 8-12-18$21 \mathrm{~m} / \mathrm{min}$ at a $0^{\circ}$ incline until the fifth week, when the running speed were gradually increased. In the last four weeks, the HIE group were run at a speed of $24 \mathrm{~m} / \mathrm{min}$ at a $0^{\circ}$ incline for $30 \mathrm{~min}$. Exercise programme completed. The treadmill speed was gradually increased so as not to increase the stress on the experimental animals (Figure 1). The exercise protocol was prepared by modifying previous studies Chen et al. (2016), Kayacan et al. (2019a).

\section{Sample Collection}

Forty-eight hours after the last exercise session (eighth week), the mice were sacrificed under deep anesthesia. Blood samples were taken from the hearts and then centrifuged at $1500 \mathrm{~g}$ for $10 \mathrm{~min}$, and the separated serum samples were collected and stored at $-86{ }^{\circ} \mathrm{C}$ for analysis. All biochemical examinations were carried out at the physiology laboratories of the Medical Faculty of Harran University in Sanliurfa, Turkey.

\section{Analysis of Thiol Disulfide Hemostasis Parameters}

The thiol disulfide homeostasis parameters in the serum samples of mice were identified by using an automated method, newly developed by Erel and Neselioglu Erel and Neselioglu (2014). According to the basic working principle of the method, dynamic disulfide bonds (-S-S) in the serum sample are reduced to functional thiol groups $(-\mathrm{SH})$ by sodium borohydride $(\mathrm{NaBH} 4)$. The residual $\mathrm{NaBH} 4$ was removed using formaldehyde to prevent the reduction of DTNB (5,5'-dithiobis-(2nitrobenzoic) acid); all thiol groups, including the reduced and native thiol groups, were determined after the reaction with DTNB (Ellman reagent) Ellman and Lysko (1979). The formulas used to calculate the dynamic disulfide bond level and other parameters are as follows: Dynamic disulfide bond (-S-S) is equal to half of the difference between total and native thiols, reduced thiol ratio as [(native thiol/total thiol) X100], oxidized thiol ratio as [(disulfide/total thiol) X100], and thiol oxidation reduction ratio as [(disulfide/native thiol) X100]. 


\section{Exercise program}
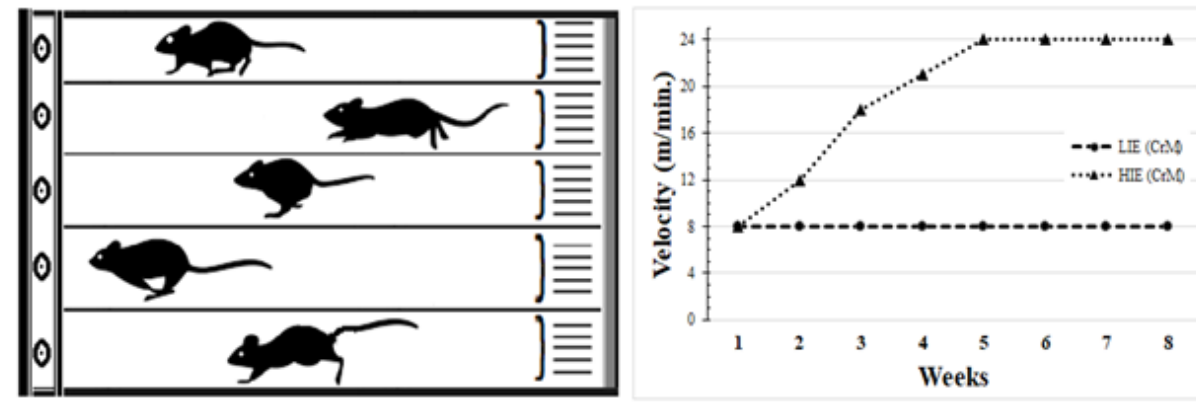

Experimental processes

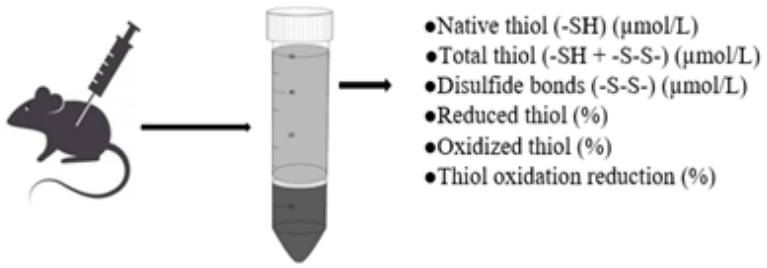

Figure 1 Experimental procedures carried out in the present study

\section{Statistical Analyses}

The minimum necessary sample size ( $\mathrm{n}: 42)$ was determined by power analysis (with an effect size of 0.60 , an $\alpha$ error probability of 0.05 , and an actual power of 0.80 ) using the GPower program (Version 3.1.9.4, Germany). The statistical analysis was carried out using the SPSS 20.0 program (SPSS Inc., Chicago, IL, USA). Data: With the histogram and Q-Q plot graphical analysis, the Shapiro-Wilk numerical evaluation and skewness-kurtosis z-score results were investigated to determine whether it showed a normal distribution. Parametric tests were used for normally distributed data. The results were presented as mean \pm standard deviation. One-way ANOVA analysis was used to compare more than two groups, and the Tukey HSD test was used for pairwise comparisons within groups. Values less than $p<0.05$ were considered statistically significant.

\section{RESULTS AND DISCUSSIONS}

In this study, 8-10 weeks old BALB/c male mice weighing $25.27 \pm 1.2 \mathrm{~g}$ obtained from Harran University Animal Experiment Application and Research Center were used. Four percent $\mathrm{CrM}$ was added to the daily diet of the groups to be supplemented with creatine and continued for 8 weeks. The groups that did not receive $\mathrm{CrM}$ supplementation were fed with standard rodent chow for 8 weeks. There was no statistical difference between the average weight changes of the groups during the 8-week exercise period $(\mathrm{p}=0.403)$ (Figure 2). 


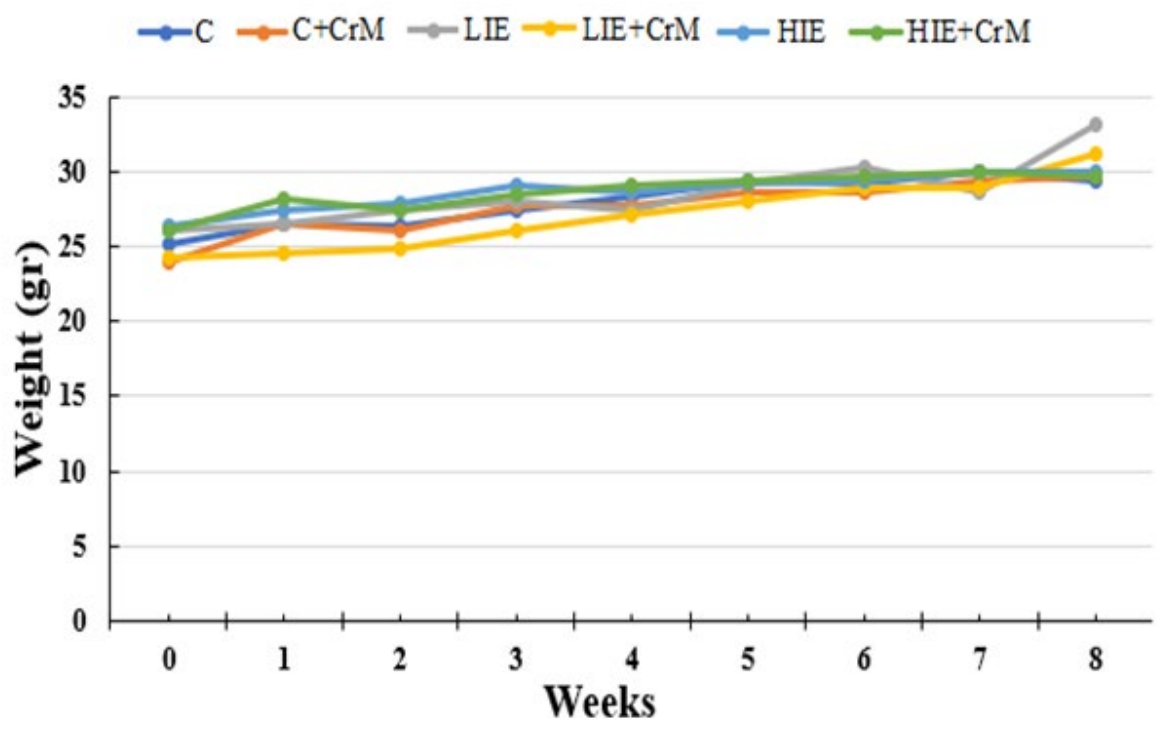

Figure 2 Weight changes of the study groups during the experimental period.

Thiol disulfide homeostasis, which is one of the best indicators of systemic oxidant-antioxidant balance in the experimental groups, was analyzed in serum samples. When the native thiol values were examined, the difference between the groups was statistically significant $(p=0.029)$. In the intragroup comparisons, we found that serum native thiol levels were statistically significantly higher in the LIE group $(5765.0 \pm 2372.4 \mu \mathrm{mol} / \mathrm{L})$ and the HIE group $(5819.1 \pm 2063.4 \mu \mathrm{mol} / \mathrm{L})$, compared to HIE+CrM group $(2372.6 \pm 876.0 \mu \mathrm{mol} / \mathrm{L})(\mathrm{p}<0.05)$.

\begin{tabular}{|c|c|c|c|c|c|c|c|}
\hline \multicolumn{8}{|c|}{ GROUPS } \\
\hline & C & $\mathrm{C}+\mathrm{CrM}$ & LIE & LIE+CrM & HIE & HIE+CrM & $p$ \\
\hline $\begin{array}{l}\text { Native thiol } \\
(\mu \mathrm{mol} / \mathrm{L})\end{array}$ & $3525.2 \pm 1443.1$ & $4213.8 \pm 1677.0$ & $\begin{array}{l}5765.0 \pm \\
2372.4 \alpha\end{array}$ & $\begin{array}{c}4279.2 \pm \\
3236.7\end{array}$ & $\begin{array}{c}5819.1 \pm \\
2063.4 \beta\end{array}$ & $2372.6 \pm 876$ & 0,029 \\
\hline $\begin{array}{l}\text { Total thiol } \\
\text { ( } \mu \mathrm{mol} / \mathrm{L})\end{array}$ & $4334.8 \pm 1547.5$ & $4836.1 \pm 1929.1$ & $\begin{array}{l}6676.8 \pm \\
2702.3^{\alpha}\end{array}$ & $\begin{array}{c}4679.8 \pm \\
3242.4\end{array}$ & $\begin{array}{c}6237.4 \pm \\
1875.0\end{array}$ & $2960.4 \pm 800.5$ & 0,035 \\
\hline $\begin{array}{l}\text { Disulfide bond } \\
(\mu \mathrm{mol} / \mathrm{L})\end{array}$ & $405.8 \pm 362.4$ & $311.1 \pm 145.8$ & $\begin{array}{l}455.8 \pm \\
216.6\end{array}$ & $\begin{array}{c}200.2 \pm \\
104.0\end{array}$ & $\begin{array}{c}262.5 \pm \\
134.8\end{array}$ & $293.8 \pm 116.1$ & 0,204 \\
\hline $\begin{array}{c}\text { Reduced thiol } \\
\text { (\%) }\end{array}$ & $81.3 \pm 12.9$ & $86.9 \pm 3.51$ & $86.4 \pm 6.2$ & $89.0 \pm 6.6$ & $90.13 \pm 5.7$ & $78.7 \pm 10.5$ & 0,093 \\
\hline $\begin{array}{c}\text { Oxidized thiol } \\
\text { (\%) }\end{array}$ & $9.3 \pm 6.4$ & $6.5 \pm 1.7$ & $6.7 \pm 3.1$ & $5.4 \pm 3.3$ & $4.5 \pm 2.8$ & $10.6 \pm 5.2$ & 0,073 \\
\hline $\begin{array}{l}\text { Thiol oxidation } \\
\text { reduction (\%) }\end{array}$ & $12.9 \pm 10.7$ & $7.5 \pm 2.4$ & $8.0 \pm 4.0$ & $6.4 \pm 4.4$ & $5.2 \pm 3.4$ & $14.6 \pm 10.3$ & 0,081 \\
\hline
\end{tabular}

Mean \pm Standard Deviation, $\alpha$ : There is a difference between LIE and HIE+CrM, $\beta$ : There is a difference between HIE and HIE+CrM (p < 0.05). C: Control, C+CrM: Control group receiving creatine monohydrate supplementation, LIE: Low intensity exercise, LIE+CrM: Low intensity exercise receiving creatine monohydrate supplementation, HIE: High intensity exercise, HIE+CrM: High intensity exercise receiving creatine monohydrate supplementation. 
A statistically significant difference was found between the groups in total thiol levels $(p=0.035)$. We found that the total thiol levels were statistically significantly higher in the LIE group $(6676.8 \pm 2702.3 \mu \mathrm{mol} / \mathrm{L})$ compared with the HIE+CrM group $(2960.4 \pm 800.5 \mu \mathrm{mol} / \mathrm{L})(\mathrm{p}<0.05)$. However, serum disulfide levels were lower in the LIE+CrM group compared to other experimental groups, but there was no statistically significant difference $(\mathrm{p}=0.204)$ (Table 1$)$.

Exercise plays an active role in maintaining a healthy life and preventing and treating many diseases. It is known that regular exercise creates beneficial adaptive responses by affecting metabolism and metabolic phenotypes in many tissues McGee and Hargreaves (2020). Exercise has been widely associated with intensitydependent free radical production and induction of oxidative stress. Although exercise intensity shifts the redox balance in favor of oxidative stress, ROS production is required for initial adaptation, and this supports the hermetic effect of exercise Thirupathi et al. (2021). The low levels of ROS induced by exercise support the formation of beneficial adaptations for health by upregulating the antioxidant defense system. However, it accelerates the formation of exerciseinduced oxidative stress with insufficient antioxidant defense against ROS formed at high levels Radak et al. (2013). Many studies have shown that oxidative stress levels and antioxidant capacity change after acute exercise Mohd Sukri (2021). In order to analyze the levels of oxidative stress induced by exercise, markers such as protein oxidation (protein carbonyls), lipid oxidation (lipid hydroperoxides, malondialdehyde), total antioxidant capacity, superoxide dismutase (SOD), and glutathione peroxidase (GPx) were widely measured in blood plasma following exercise Wadley et al. (2016), Ammar et al. (2020).

In a study examining the effects of aerobic, anaerobic, and combined exercises on oxidative stress, it was determined that plasma MDA levels increased after exercise in all three exercise groups. However, an increase in antioxidant activities (SOD and GPX) was also observed. It was concluded that exercise has the potential to increase oxidative stress and antioxidant capacity, but there are different response sizes according to its intensity and duration Ammar et al. (2020). However, in another study, it was stated that acute exercise increased the level of oxidative stress, which could negatively affect muscle function in elderly individuals Nikolaidis (2017).

It has been reported that ROS levels increased at $70 \%$ and higher intensities when participants had cycling exercise at different intensities (40\%, 55\%, 70\%, $85 \%$, and $100 \%$ of VO2max) Parker et al. (2014). In another study, the effects of three different exercise sessions (moderate-intensity concentric and eccentric cycling and high-intensity eccentric cycling) performed on participants on oxidative stress and muscle damage levels were analyzed. It has been reported that oxidative stress is minimal after eccentric cycling, but that high-intensity eccentric cycling causes moderate muscle damage González-Bartholin et al. (2019). In a study conducted with 10 male participants, different exercise protocols were applied to the subjects, and their acute changes in oxidative stress were analyzed. The results showed that the oxidative stress responses elicited following exercise practices did not induce a significantly different response in plasma markers Wadley et al. (2016). The oxidative stress response may depend on the intensity and duration of the exercise.

Thiol disulfide homeostasis is accepted as the most current oxidative stress marker in the literature. Dynamic thiol disulfide homeostasis has been investigated in many conditions thought to be associated with oxidative stress Celik et al. (2019a), Kayacan et al. (2019b). In a study investigating the redox status and 
antioxidant capacities of subjects in three different categories: sedentary, regular exercise, and obese, it was found that the highest total thiol value was in the group that regularly exercised. However, higher disulfide levels were found in the exercising group compared to the other groups Gol et al. (2019). Similarly, another study showed that exercise application causes an increase in total thiol levels Celik et al. (2019b). On the contrary, in a similar study, after four weeks of exercise, a higher total thiol value was found in the control group compared with the exercisetreated groups. In the same study, the lowest disulfide level was determined in the group that did moderately intensive exercise Kayacan et al. (2019a). Researchers have reported that regular exercise develops resistance to oxidative damage by causing adaptation in body systems Kayacan et al. (2018).

In this study, exercise increased native thiol and total thiol levels independently of creatine supplementation. This surge is thought to be indicative of an increased thiol pool in response to regular exercise. While native thiol and total thiol levels increased in the $\mathrm{C}+\mathrm{CrM}$ group receiving creatine supplementation, they decreased in the LIE+CrM and HIE+CrM groups. Creatine intake with exercise decreased native thiol and total thiol levels. In particular, the lowest native thiol and total thiol levels were found in the high-intensity exercise group receiving creatine supplementation. This may be due to the potential antioxidant properties of creatinine Stefani et al. (2014). Oxidative stress during exercise is thought to be compensated by creatine rather than thiol groups. Likewise, the fact that the disulfide levels in the LIE+CrM and HIE+CrM groups were lower than those in the non-supplemented LIE and HIE groups supports this hypothesis. The disulfide level, which is considered an early indicator of oxidative stress, was the lowest in the LIE+CrM group among all groups. It is thought that this effect is caused by the structural feature of creatine, or it is created by interacting with different molecules during exercise.

Creatine supplementation can accelerate recovery time between bouts of intense exercise by maintaining oxidant-antioxidant homeostasis at an optimal level, reducing muscle damage and promoting faster recovery of lost power generation potential Wax et al. (2021).

\section{CONCLUSIONS AND RECOMMENDATIONS}

These findings showed that CrM supplementation with LIE improved antioxidant capacity and was significantly effective in preventing oxidative damage. It is possible that the effects of CrM supplementation on the oxidant-antioxidant system are related to the intensity of exercise. Creatine supplementation has a synergistic effect with exercise, but the intensity, duration, and period of $\mathrm{CrM}$ supplementation of exercise will be critical in all these effects. It is thought that creatine supplementation with exercise reduces the thiol-disulfide homeostasis burden of the organism, and that after the depletion of creatine stores, the sustainability of oxidant-antioxidant homeostasis can be extended, thus prolonging the duration of antioxidant resistance

\section{REFERENCES}

Ammar, A., Trabelsi, K., Boukhris, O., Glenn, J. M., Bott, N., Masmoudi, L., Hakim, A., Chtourou, H., Driss, T., Hoekelmann, A., \& Abed, K. El. (2020). Effects of aerobic-, anaerobic- and combined-based exercises on plasma oxidative stress biomarkers in healthy untrained young adults. International Journal of Environmental Research and Public Health, 17(7). Retrieved from https://doi.org/10.3390/ijerph17072601 
Antonio, J., Candow, D. G., Forbes, S. C., Gualano, B., Jagim, A. R., Kreider, R. B., Rawson, E. S., Smith-Ryan, A. E., VanDusseldorp, T. A., Willoughby, D. S., \& Ziegenfuss, T. N. (2021). Common questions and misconceptions about creatine supplementation: what does the scientific evidence really show? Journal of the International Society of Sports Nutrition, 18(1), 1-17. Retrieved from https://doi.org/10.1186/s12970-021-00412-w

Bediz, C. Ş. (2020). Egzersizde Enerji Metabolizması. In E. Ağar (Ed.), İnsan Fizyolojisi (pp. 833-842). İstanbul Tıp Kitabevleri.

Brunetta, H. S., Holwerda, A. M., van Loon, L. J. C., \& Holloway, G. P. (2020). Mitochondrial ROS and Aging: Understanding Exercise as a Preventive Tool. Journal of Science in Sport and Exercise, 2(1), 15-24. Retrieved from https://doi.org/10.1007/s42978-019-00037-1

Cao, W., Li, M., Wu, T., Feng, F., Feng, T., Xu, Y., \& Sun, C. (2017). $\alpha$ MSH prevents ROSinduced apoptosis by inhibiting Foxo1/mTORC2 in mice adipose tissue. Oncotarget, 8(25), 40872-40884. Retrieved from https://doi.org/10.18632/oncotarget.16606

Celik, H., Kilic, T., Kaplan, D. S., Eren, M. A., Erel, O., Karakilcik, A. Z., \& Bagci, C. (2019a). The effect of newly initiated exercise training on dynamic Thiol/disulphide homeostasis in sedentary obese adults. Anais Da Academia Brasileira de Ciencias, 91(4), 1-10. Retrieved from https://doi.org/10.1590/0001-3765201920180930

Celik, H., Kucuk, M., Aktas, Y., Zerin, M., Erel, O., Neselioglu, S., \& Kaplan, D. S. (2019b). The protective effects of pistachio nut (Pistacia vera L.) on thiol/disulfide homeostasis in young soccer players undergoing a strenuous exercise training program. Acta Medica Mediterranea, 35(2), 893-897. Retrieved from https://doi.org/10.19193/0393-6384_2019_2_135

Chen, X., Li, L., Guo, J., Zhang, L., Yuan, Y., Chen, B., Sun, Z., Xu, J., \& Zou, J. (2016). Treadmill running exercise prevents senile osteoporosis and upregulates the Wnt signaling pathway in SAMP6 mice. Oncotarget, 7(44), 71072-71086. Retrieved from https://doi.org/10.18632/oncotarget.12125

Ellman, G., \& Lysko, H. (1979). A precise method for the determination of whole blood and plasma sulfhydryl groups. Analytical Biochemistry, 93(C), 98-102. Retrieved from https://doi.org/10.1016/S0003-2697(79)80122-0

Erel, O., \& Neselioglu, S. (2014). A novel and automated assay for thiol/disulphide homeostasis. Clinical Biochemistry, 47(18), 326-332. Retrieved from https://doi.org/10.1016/j.clinbiochem.2014.09.026

Gastin, P. B. (2001). Energy system interaction and relative contribution during maximal exercise. Sports Medicine, 31(10), 725-741. Retrieved from https://doi.org/10.2165/00007256-200131100-00003

Gol, M., Özkaya, B., Yildirim, C., \& Bal, R. (2019). Regular exercise, overweight/obesity and sedentary lifestyle cause adaptive changes in thioldisulfide homeostasis. Anais Da Academia Brasileira de Ciencias, 91(2), e20180547. Retrieved from https://doi.org/10.1590/00013765201920180547

González-Bartholin, R., Mackay, K., Valladares, D., Zbinden-Foncea, H., Nosaka, K., \& Peñailillo, L. (2019). Changes in oxidative stress, inflammation and muscle damage markers following eccentric versus concentric cycling in older adults. European Journal of Applied Physiology, 119(10), 2301-2312. Retrieved from https://doi.org/10.1007/s00421-019-04213-7 
Hargreaves, M., \& Spriet, L. L. (2020). Skeletal muscle energy metabolism during exercise. Nature Metabolism, 2(9), 817-828. Retrieved from https://doi.org/10.1038/s42255-020-00290-7, https://doi.org/10.1038/s42255-020-0251-4

Harris, R. C., Söderlund, K., \& Hultman, E. (1992). Elevation of creatine in resting and exercised muscle of normal subjects by creatine supplementation. Clinical Science, 83(3), 367-374. Retrieved from https://doi.org/10.1042/cs0830367

Havenetidis, K. (2016). The use of creatine supplements in the military. Journal of the Royal Army Medical Corps, 162(4), 242-248. Retrieved from https://doi.org/10.1136/jramc-2014-000400

Kayacan, Y., Çetinkaya, A., Yazar, H., \& Makaracı, Y. (2019a). Oxidative stress response to different exercise intensity with an automated assay: thiol/disulphide homeostasis. Archives of Physiology and Biochemistry, 15. Retrieved from https://doi.org/10.1080/13813455.2019.1651868

Kayacan, Y., Yazar, H., Cerit, G., \& Ghojebeigloo, B. E. (2019b). A new oxidative stress indicator: Effect of 5-hydroxytryptophan on thiol-disulfide homeostasis in exercise. Nutrition, 63-64, 114-119. Retrieved from https://doi.org/10.1016/j.nut.2019.01.013

Kayacan, Y., Yazar, H., Kisa, E. C., \& Ghojebeigloo, B. E. (2018). A novel biomarker explaining the role of oxidative stress in exercise and l-tyrosine supplementation: thiol/disulphide homeostasis. Archives of Physiology and Biochemistry, 124(3), 232-236. Retrieved from https://doi.org/10.1080/13813455.2017.1388410

Kreider, R. B. (2003). Effects of creatine supplementation on performance and training adaptations. Molecular and Cellular Biochemistry, 244(1-2), 89-94. Retrieved from https://doi.org/10.1023/A:1022465203458

Leem, Y.-H., Kato, M., \& Chang, H. (2018). Regular exercise and creatine supplementation prevent chronic mild stress-induced decrease in hippocampal neurogenesis via Wnt/GSK3 $\beta / \beta$-catenin pathway. Journal of Exercise Nutrition \& Biochemistry, 22(2), 1-6. Retrieved from https://doi.org/10.20463/jenb.2018.0009

Lü, J. M., Lin, P. H., Yao, Q., \& Chen, C. (2010). Chemical and molecular mechanisms of antioxidants: Experimental approaches and model systems. Journal of Cellular and Molecular Medicine, 14(4), 840-860. Retrieved from https://doi.org/10.1111/j.1582-4934.2009.00897.x

McGee, S. L., \& Hargreaves, M. (2020). Exercise adaptations: molecular mechanisms and potential targets for therapeutic benefit. Nature Reviews Endocrinology, 16(9), 495-505. Retrieved from https://doi.org/10.1038/s41574-020-0377-1

Moghetti, P., Bacchi, E., Brangani, C., Donà, S., \& Negri, C. (2016). Metabolic Effects of Exercise. Frontiers of Hormone Research, 47, 44-57. Retrieved from https://doi.org/10.1159/000445156

Mohd Sukri, N. (2021). Does vitamin C minimise exercise-induced oxidative stress? Sport Sciences for Health, 17(3), 505-533. Retrieved from https://doi.org/10.1007/s11332-021-00756-5

Momaya, A., Fawal, M., \& Estes, R. (2015). Performance-Enhancing Substances in Sports: A Review of the Literature. Sports Medicine, 45(4), 517-531. Retrieved from https://doi.org/10.1007/s40279-015-0308-9 
Murphy, M. P. (2009). How mitochondria produce reactive oxygen species. Biochemical Journal, 417(1), 1-13. Retrieved from https://doi.org/10.1042/BJ20110539, https://doi.org/10.1042/BJ20081386

Nikolaidis, M. G. (2017). The effects of resistance exercise on muscle damage, position sense, and blood redox status in young and elderly individuals. $\begin{array}{llll}\text { Geriatrics } & \text { (Switzerland), } & \text { 2(3). } & \text { Retrieved }\end{array}$ https://doi.org/10.3390/geriatrics2030020

Parker, L., Mcguckin, T. A., \& Leicht, A. S. (2014). Influence of exercise intensity on systemic oxidative stress and antioxidant capacity. Clinical Physiology and Functional Imaging, 34(5), 377-383. Retrieved from https://doi.org/10.1111/cpf.12108

Poortmans, J. R., Rawson, E. S., Burke, L. M., Stear, S. J., \& Castell, L. M. (2010). A-Z of nutritional supplements: Dietary supplements, sports nutrition foods and ergogenic aids for health and performance Part 11. British Journal of Sports Medicine, 44(10), 765-766. Retrieved from https://doi.org/10.1136/bjsm.2010.076117

Radak, Z., Zhao, Z., Koltai, E., Ohno, H., \& Atalay, M. (2013). Oxygen consumption and usage during physical exercise: The balance between oxidative stress and ROS-dependent adaptive signaling. Antioxidants and Redox Signaling, 18(10), 1208-1246. Retrieved from https://doi.org/10.1089/ars.2011.4498

Stefani, G. P., Nunes, R. B., Dornelles, A. Z., Alves, J. P., Piva, M. O., Domenico, M. Di, Rhoden, C. R., \& Lago, P. D. (2014). Effects of creatine supplementation associated with resistance training on oxidative stress in different tissues of rats. Journal of the International Society of Sports Nutrition, 11(1), 11. Retrieved from https://doi.org/10.1186/1550-2783-11-11

Thirupathi, A., Wang, M., Lin, J. K., Fekete, G., István, B., Baker, J. S., \& Gu, Y. (2021). Effect of Different Exercise Modalities on Oxidative Stress: A Systematic Review. In BioMed Research International (Vol. 2021). Retrieved from https://doi.org/10.1155/2021/1947928

Vargas-Mendoza, N., Morales-González, Á., Madrigal-Santillán, E. O., MadrigalBujaidar, E., Álvarez-González, I., García-Melo, L. F., Anguiano-Robledo, L., Fregoso-Aguilar, T., \& Morales-Gonzalez, J. A. (2019). Antioxidant and adaptative response mediated by Nrf2 during physical exercise. $\begin{array}{llll}\text { Antioxidants, } & 8(6) \text {. } & \text { Retrieved }\end{array}$ https://doi.org/10.3390/antiox8060196

Wadley, A. J., Chen, Y. W., Lip, G. Y. H., Fisher, J. P., \& Aldred, S. (2016). Low volumehigh intensity interval exercise elicits antioxidant and anti-inflammatory effects in humans. Journal of Sports Sciences, 34(1), 1-9. Retrieved from https://doi.org/10.1080/02640414.2015.1035666

Wallimann, T., Tokarska-Schlattner, M., \& Schlattner, U. (2011). The creatine kinase system and pleiotropic effects of creatine. Amino Acids, 40(5), 1271-1296. Retrieved from https://doi.org/10.1007/s00726-011-0877-3

Waris, G., \& Ahsan, H. (2006). Reactive oxygen species: Role in the development of cancer and various chronic conditions. Journal of Carcinogenesis, 5, 1-8. Retrieved from https://doi.org/10.1186/1477-3163-5-14, https://doi.org/10.1186/1477-3163-5-1 
Wax, B., Kerksick, C. M., Jagim, A. R., Mayo, J. J., Lyons, B. C., \& Kreider, R. B. (2021). Creatine for Exercise and Sports Performance, with Recovery Considerations for Healthy Populations. Nutrients, 13, 1-42. Retrieved from https://doi.org/10.3390/nu13061915 